\title{
Anti-hypertensive activity of aqueous and methanolic leaf extracts of Schleichera oleosa (Lour.) Merr
}

\begin{abstract}
Present study was undertaken to investigate phytochemical, nitric oxide scavenging activity and antihypertensive activity of the methanolic and aqueous leaf extracts of S. oleosa. The phytochemical analysis carried out revealed the presence of flavanoids, glycosides, alkaloids, tannins, saponins and steroids and many other metabolites. Both the extracts showed high NOSA (33.81\% and $31.43 \%$ NOSA at $100 \mu \mathrm{g}$ concentration). The methanolic leaf extract showed $1.6 \%, 4 \%$, and $5.6 \%$ ACE inhibition against $10 \mu \mathrm{g}, 50 \mu \mathrm{g}$ and $100 \mu \mathrm{g}$ concentration respectively and aqueous leaf extract of $S$. oleosa showed very negligible percentage that is $0 \%, 0 \%$ and $0.8 \%$ ACE inhibition against $10 \mu \mathrm{g}, 50 \mu \mathrm{g}$ and $100 \mu \mathrm{g}$ extract concentration respectively while Captopril showed 100\% ACE inhibition against all the three concentrations. The result shows that the methanolic as well as the aqueous leaf extracts of Schleichera oleosa are not very good antihypertensive agents. However the methanolic leaf extract of Schleichera oleosa is a better antihypertensive inhibitor than the aqueous leaf extract.
\end{abstract}

Keywords: captopril, hypertensive, phytochemical, radical scavenging
Volume 8 Issue 3 - 2019

\author{
Sophy Jose,' Sukumar Dandapat,' \\ Manoranjan Prasad Sinha ${ }^{1,2}$ \\ 'Department of Zoology, Ranchi University, India \\ ${ }^{2}$ Vice Chancellor, Sidho Kanhu Murmu University, India
}

Correspondence: Sukumar Dandapat, Department of Zoology, Ranchi University, Ranchi-834008, Jharkhand, India, Email dr.sukumar2018@gmail.com

Received: February 24, 2019 | Published: May 01, 2019
Abbreviations: HEPES, 4-(2-hydroxyethyl)-1piperazineethanesulfonic acid; ACE, angiotensin-converting enzyme; ELISA, enzyme-linked immunosorbent assay; NOSA, nitric oxide scavenging activity; ME, methanolic extract; $\mathrm{AE}$, aqueous extract; ROS, reactive oxygen species; NO, nitric oxide; RNS, reactive nitrogen species

\section{Introduction}

Diseases related to heart and circulatory systems are the reasons for 12 million deaths every year globally and are known to be the major group of killer disease. ${ }^{1}$ Hypertension is the most common problem associated with cardiovascular disease and constituents a major factor for several cardiovascular pathologies including atherosclerosis, coronary artery disease, myocardial infract heart failure, renal insufficiency, stroke and dissecting aneurysm of aorta and is one of the leading causes of disability, mortality and morbidity along the population and it is the most common chronic illness faced in the world specially developing countries. ${ }^{2,3}$

Because of high incidence and morbidity, various drugs and regimes have been advocated for the control of hypertension. Many new drugs have also been introduced which may demonstrate better efficacy but possess side effects. ${ }^{4}$ Recently, attention has been focused towards herbal and mineral preparations which are traditionally used as potential therapeutic agents in the prevention and management of cardiovascular diseases and hypertensive agent. ${ }^{5}$

Genus Schleichera is belonging to the soapberry family Sapindaceae and is generally found in Indian subcontinent and in mixed deciduous forests and in Southeast Asia. ${ }^{6}$ Schleichera oleosa has been used in traditional medicine and its leaf, seed, oil and bark are used for curing itch, burns, acne pain etc., and it promotes hair growth, treats rheumatism, head ache, skin diseases, malarial fever and is prophylactic against cholera.?

Screening of proximate phytochemicals and in vitro antihypertensive activity of the leaf extracts of $S$. oleosa has not been explored previously. The present study was undertaken to screen the proximate phytochemical composition and in vitro antihypertensive activities of the aqueous and methanolic leaf extracts of $S$. oleosa.

\section{Materials and methods}

\section{Collection of plant material}

The fresh mature leaves of the plant were collected and identified. The leaves were washed and dried in shade under room temperature for six to seven days and then crushed into coarse powder using electric grinder. The powder was sieved to get fine powder using fine plastic sieve which was stored in air tight bottle in the laboratory until required.

\section{Extract preparation}

$50 \mathrm{~g}$ of the powder was subjected to extraction by soxhlet using methanol $(300 \mathrm{~mL})$ and distilled water $(300 \mathrm{~mL})$ separately. The extracts obtained were filtered, concentrated after dryness in rotary flash evaporator maintained at $45^{\circ} \mathrm{C}$. Percentage yield of each extract was calculated and the dried extracts were stored in airtight containers at room temperature for further studies.

\section{Phytochemical analyses}

Freshly prepared extracts of the powdered leaves were subjected to phytochemical analyses to find the presence of the following phyto constituents such as flavanoids, alkaloids, carbohydrates, glycosides, polysaccharides, tannins, saponins, steroids, proteins, lipids, oils by standard methods of Arya et al., ${ }^{9}$ and total phenol and flavonoid was estimated by previous methods of Dandapat et al. ${ }^{10}$

\section{Nitric oxide radical scavenging activity}

NOSA was performed as per previous method of Kumar et al., ${ }^{11}$ $10 \mu \mathrm{g}, 50 \mu \mathrm{g}$ and $100 \mu \mathrm{g}$ concentrations of aqueous and methanolic plant extract and Butylated hydroxy anisole (BHA) were taken in different test tubes and made up to $3 \mathrm{ml}$ with $0.1 \mathrm{M}$ phosphate buffer 
( $\mathrm{pH}$ 7.2). Sodium Nitroprusside $(5 \mathrm{mM})$ prepared in buffered saline $(\mathrm{pH} 7.2)$ was added $(1 \mathrm{ml})$ to each tube and made final sample for nitric oxide radical scavenging test. The reaction mixture (final sample) was incubated for $30 \mathrm{~min}$ at RT. A control (methanol) equivalent amount to final sample without the extract was maintained. After $30 \mathrm{~min}, 1.5 \mathrm{ml}$ of above solution was mixed with $1.5 \mathrm{ml}$ of Griess reagent $(1 \%$ Sulphanilamide, $2 \%$ phosphoric acid and $0.1 \% \mathrm{~N}-1-$ Naphthylethylenediamine dihydrochloride). The absorbance of the samples was measured at $546 \mathrm{~nm}$. Nitric oxide radical scavenging activity was calculated using the following formula:

$$
\% \text { NOSA }=\frac{(\text { Control OD }- \text { sample OD })}{\text { Control OD }} \times 100
$$

\section{Estimation of antihypertensive activity}

Estimation of antihypertensive activity was performed as per as previous method of Hooper et al. ${ }^{12}$ Jimsheena et al., ${ }^{13} 10 \mu \mathrm{g}, 50 \mu \mathrm{g}$ and $100 \mu \mathrm{g}$ of $S$. oleosa aqueous and methanolic leaf extract was tested for antihypertensive activity. Plant extracts were dissolved in methanol and mixed with $10 \mathrm{mM}$ HEPES assay buffer $(0.3 \mathrm{M} \mathrm{NaCl}$ and $10 \mu \mathrm{M}$ Zinc Sulphate), $20 \mu \mathrm{L}$ kidney cortex plasma membranes (ACE enzyme source) and 1mM Hippuryl-His-Leu as substrate. The mixture was incubated for 10 minutes at $37^{\circ} \mathrm{C}$. Then $10 \mu \mathrm{L}$ of substrate $(1 \mathrm{mM})$ was added which makes a final reaction volume of $50 \mu \mathrm{L}$ and furter incubated for $45 \mathrm{~min}$ at $37^{\circ} \mathrm{C}$. The reaction is terminated by the addition of $1 \mathrm{M} \mathrm{HCl}(0.1 \mathrm{~mL})$. The yellow color is developed by the addition of $100 \mu \mathrm{L}$ of pyridine and $50 \mu \mathrm{L}$ of Benzene sulphonyl chloride. The yellow color that formed is measured at $410 \mathrm{~nm}$ in an ELISA plate reader (iMARK, BIORAD). Compounds with an inhibitory potential block the substrate availability to the enzyme and thereby cause enzyme inhibition leading to no formation of yellow color. The inhibition is represented in the form of percentage over control. Captopril, a known ACE inhibitor is tested in this assay as a standard compound. The same procedure was used for aqueous extract to analyze for its antihypertensive activity.

\section{Results}

\section{Phytochemicla screening}

Resuts of proximate qualitative phytochemical screening of $S$. oleosa methanolic and aqueous extract is presented in Table 1. Results revealed the extracts contain carbohydrates, glycosides, polysaccharides, proteins alkaloids, steroids triterpenes, flavanoids, tannins. Quantitative estimation of total flavonoid and total phenolics are presented in Figure 1. The results of quantitative estimation of total flavonoid and total phenolics content of the extract showed that, both total flavonoid $(168.89 \mu \mathrm{g} / \mathrm{mg})$ and total phenolics $(20.00 \mu \mathrm{g} / \mathrm{mg})$ content of methanolic extract are high than aqueous leaf extracts of S. oleosa.

\section{Nitricoxide radical scavenging activity}

Results of NOSA of methanolic and aqueous leaf extracts of $S$. oleosa are present in Figure 2. Results revealed the NOSA of BHA $(6.19 \%, 28.57 \%$ and $42.86 \%)$ is higher than the extracts but the methanolic $(7.14 \%, 13.33 \%$ and $33.81 \%)$ extract showed high NOSA than aqueous extract $(1.90 \%, 10.00 \%$ and $31.43 \%)$.

\section{Antihypertensive activity}

The antihypertensive efficacy of the extracts of $S$. oleosa leaves was quantitatively assessed on the basis of ACE inhibition percentage and compared with standard ACE inhibitor Captopril. The results of are shown in Table 2. Antihypertensive activity of Captoprill was also tested against the same concentration of extracts to compare antihypertensive efficacy of $S$. oleosa leaf extracts. The methanolic leaf extract showed $1.6 \%, 4 \%$, and $5.6 \% \mathrm{ACE}$ inhibition against $10 \mu \mathrm{g}$, $50 \mu \mathrm{g}$ and $100 \mu \mathrm{g}$ concentration respectively and aqueous leaf extract of $S$. oleosa showed very negligible percentage that is $0 \%, 0 \%$ and 0.8 ACE inhibition against $10 \mu \mathrm{g}, 50 \mu \mathrm{g}$ and $100 \mu \mathrm{g}$ extract concentration respectively while Captopril showed $100 \%$ ACE inhibition against all the three concentrations.

Table I Proximate Phytochemical composition of Methanolic and aqueous extracts of S. oleosa

\begin{tabular}{lll}
\hline Phytochemicals & ME & AE \\
\hline Carbohydrates & + & + \\
Glycosides & + & + \\
Polysaccharides & + & - \\
Proteins & + & + \\
Alkaloids & + & + \\
Steroids & + & + \\
Triterpenes & + & - \\
Flavanoids & + & - \\
Tannins & + & - \\
Lipid & - & + \\
Oils & + & + \\
Saponins & - & +
\end{tabular}

Table 2 Showing the ACE inhibition of S. oleosa methanolic leaf extract, aqueous leaf extract and Captoprill

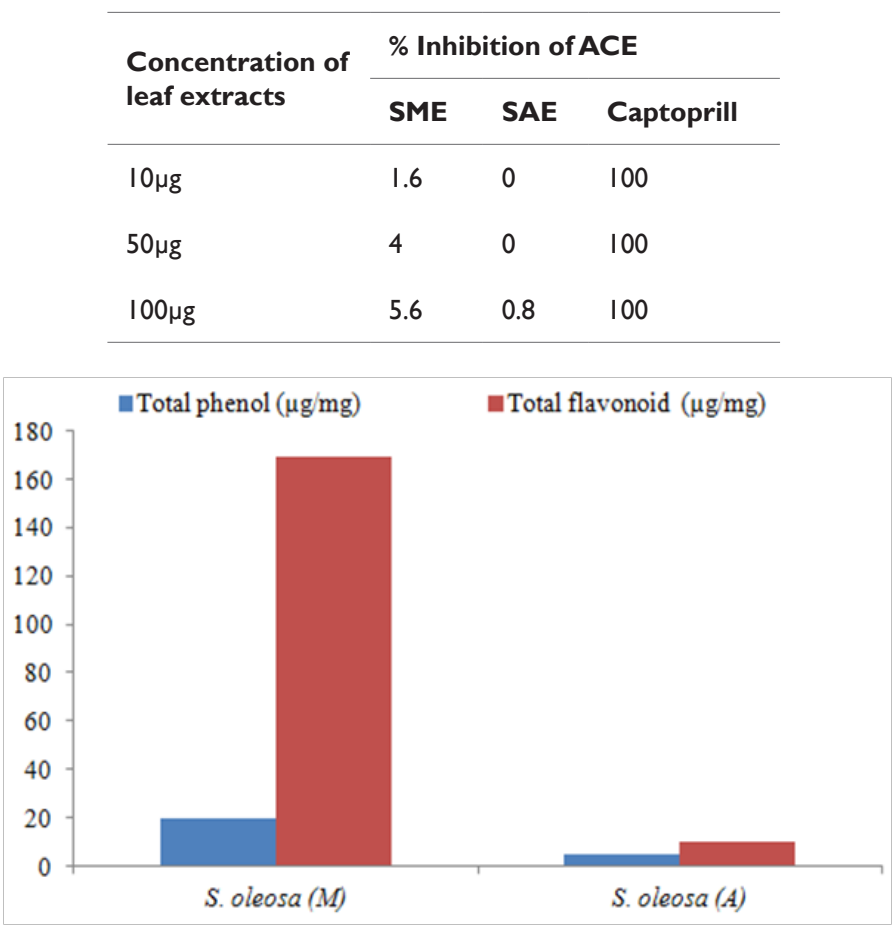

Figure I Total phenol and flavonid content of S. oleosa M (methanolic) and A (aqueous) extracts. 


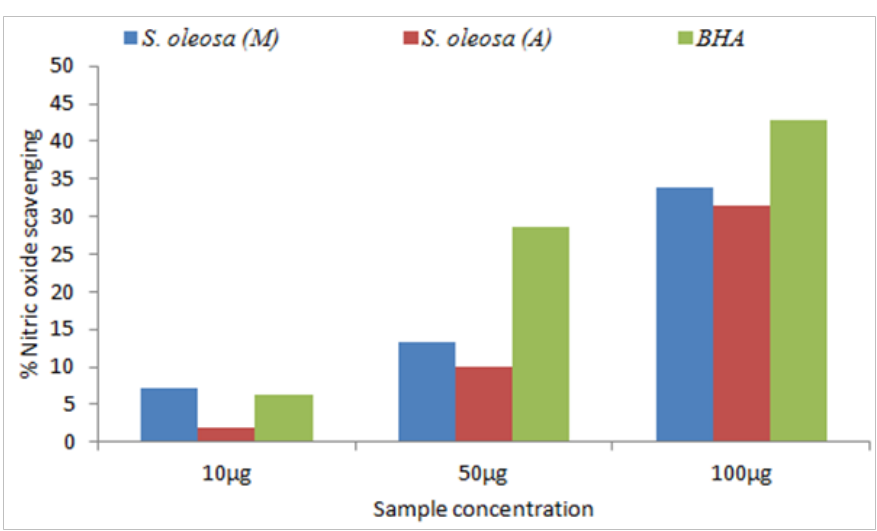

Figure 2 Nitricoxide radical scavenging activity of S. oleosa methanolic (M), aqueous $(\mathrm{A})$ leaf extract and $\mathrm{BHA}$.

\section{Discussion}

These constituents are responsible for the curative nature of Schelichera oleosa against itching, head ache, malaria, skin diseases etc. which could make the plant useful for treating different ailments and having a potential of providing useful and safe drugs and drug leads for human use. ${ }^{14}$ Biochemicals of plants natural substances such as plants, mushrooms and algae etc. posses antioxidants activity which are associated with reduction of free radicals, modulation of immune system, pathogen suppression and health protective activities and many other therapeutic activities. ${ }^{15,16}$ Previous in vitro antioxidant capacity and free radical scavenging evaluation of active metabolite constituents of Newbouldia laevis ethanolic leaf extract and found concentration dependent NOSA which are associated phytochemicals such as phenol, flavonoid, saponins, tannins, vitamins etc. ${ }^{17}$ Phenolic compounds polyphenolic compounds such as flavonoids, tannins and alkaloids are found in the edible and inedible parts of plants portray antioxidant activity and mainly due to their redox properties, which allows them to act as reducing agents, hydrogen donors and singlet oxygen quenchers or metal chelators ${ }^{18-20}$ hence they play antioxidizing effects reduces the free radical generation. In present study S. oleosa leaf extracts also contain different types of phytochemicals and high phenolic and polyphenolic content which may associate with free radical scavenging and antihypertensive activity and other medicinal properties. Oxidative stress is one of the major key factor that promotes pathogenesis of hypertension in human and other mammals. ${ }^{21}$ Endothelial cells play a major role in the contraction and relaxation of blood vessels. They release nitric oxide which impart in vasorelaxation and maintain normal blood pressure. ${ }^{22,23}$ Reactive nitrogen species such as nitric oxide synthase (NOS), and in particular the endothelial isoform of NOS (eNOS), are now recognized as an important source of superoxide anions which combine with other reactive oxygen species (ROS) suppress the production of nitrous oxide (NO) and form nitrosative stress, damage the cells, decrease atherogenic stimuli for NOS coupling and NO production and promote vasoconstriction. ${ }^{24,25}$ It has also been reported that, eNOS become a peroxynitrite generator of free radicals, leading to a dramatic increase in oxidative stress, since peroxynitrite formed by the NO-superoxide reaction has additional detrimental effects on vascular function by oxidation of cellular proteins and lipids. ${ }^{23,26}$ It has been reported that reactive nitrogen species (RNS) such as $\mathrm{NO}_{2}, \mathrm{~N}_{3} \mathrm{O}_{4}, \mathrm{~N}_{2} \mathrm{O}_{4}$ etc. are associated with NO-superoxide reaction but reduction in the excess level of NO in human body by taking antioxidant rich plant products can lower the risks of various pathophysiological actions such as elevated inflammation, hypertension, cancer etc and maintained good health status. ${ }^{27}$ Earlier works on ACE inhibition by plants like Lippia nodiflora have shown positive results. ${ }^{28}$ The standard chemotherapeutic drugs include direct vasodilation of the blood vessel, blocking of calcium channels, inhibition of $\alpha$-adrenoreceptor response, induction of negative ionotropic response of smooth muscle, inhibition of platelet aggregation, reduction of vascular resistance, and improvement of pulmonary oxygen utilization. ${ }^{29,30}$ It has been reported that enhanced activity of nitric oxide and improved handling of intracellular calcium has also been found to play a critical role in the reduction of vascular resistance and blood pressure that are elevated in hypertensive rats and humans. ${ }^{31}$ The antihypertensive effects of plants are associated with their antioxidant properties because oxidative stress is considered a major risk factor in hypertension and cardiovascular diseases. ${ }^{32}$ In previous research free radical and nitric oxide radical scavenging activity of five medicinal plants Spatholobus suberectus, Uncaria rhynchophylla, Alpinia officinarum, Drynaria fortunei and Crataegus pinnatifida traditionally used for the treatment of hypertension have been studied and reported these plants contains various kinds of phytochemicals such as phenols and polyphenols, alkaloid etc. effectively reduced free radicals. ${ }^{33}$ Njoya EM et al., ${ }^{34}$ also worked on free radical scavenging activities of Sarcocephalus pobeguinii extracts and reported the extract inhibit formation of free radicals and reduces nitric oxide radicals which are associated with pathogenesis of hyper tension. In present work S. oleosa leaf extract inhibits the nitric oxide radicals and also posse antihypertensive activity which correlates with previous studies.

\section{Conclusion}

S. oleosa leaf extract contain various phytochemicals but phenols and polyphenolic phytochemicals are found in high concentration. In vitro nitric oxide radical scavenging activity of the extracts are not high than synthetic antioxidant BHA. Methanolic extract of S. oleosa showed high antihypertensive activity compare to aqueous extract but their antihypertensive activity is quite low compare to standard Captopril. Thus from the present work it can be concluded S. oleosa leaf extract possess antioxidant and antihypertensive properties. Further, more extensive in vivo work on animal model will be required.

\section{Acknowledgments}

The authors acknowledge the facilities provided by Department of Zoology, Ranchi University, Ranchi, India for carrying out the work.

\section{Conflicts of interest}

There is no conflict of interest among the authors.

\section{References}

1. Sakat SS, Wankhede SS, Juvekar AR, et al. Antihypertensive effect of aqueous extract of Elaeocarpus ganitrus Roxb. seeds in renal artery occluded hypertensive rats. Int J Pharm Tech Res. 2009;1(3):779-782.

2. Ofem OE, Eno AE, Imoru J, et al. Effect of crude aqueous leaf extract of Visum album (mile stone) on hypertensive rats. Ind J Pharmacol. 2017;39(1):15-19.

3. Lim SS, Vos T, Flaxman AD, et al. A comparative risk assessment of burden of disease and injury attributable to 67 risk factors and risk factor clusters in 21 regions, 1990-2010: a systematic analysis for the global burden of disease study 2010. Lancet. 2012;380(9859):2224-2260. 
4. Pal SK, Shukla Y. Herbal medicine: current status and the future. Asian Pac J Cancer Prev. 2003;4:281-299.

5. Sumazian Y, Syahida A, Hakiman M, et al. Antioxidant activities, flavonoids, ascorbic acid and phenolic contents of Malaysian vegetables. $J$ Med Plant Res. 2010;4(10):881-890.

6. Jose S, Sinha MP. Study of antibacterial efficacy of methanolic and aqueous leaf extracts of Scoparia dulcis on some human pathogenic bacteria. Int J Curr Microbiol App Sci.2017;6(1):423-432.

7. Palanuvej C, Vipunngeun N. Fatty acid constituents of Schleichera oleosa (Lour) Oken seed oil. J Health Res. 2008;22:203-212.

8. Dandapt S, Sinha MP. Antioxidant and anti-inflammatory activity of Pleurotus tuber-regium (Rumph. ex Fr.) Singer. Adv Biol Res. 2015;9(3):140-145.

9. Arya V, Thakur N, Kashyap CP. Preliminary phytochemical analysis of the extracts of Psidium leaves. J Pharmacogn Phytochem. 2012;1(1):1-6.

10. Dandapt S, Kumar A, Sinha MP. Assessment of Bioactivity of Cinnamomum tamala (Buch.-Ham.). Turk J Agri-Food Sci Technol. 2015;3(3):121-125.

11. Kumar S, Kumar D, Manjusha, et al. Antioxidant and free radical scavenging potential of Citrullus colocynthis (L.) Schrad. methanolic fruit extract. Acta Pharm. 2008;58(2):215-220.

12. Hooper NM, Turner AJ. Isolation of two differentially glycosylated forms of peptidyl-dipeptidase A (angiotensin converting enzyme) from pig brain: a re-evaluation of their role in neuropeptide metabolism. Biochem J. 1987;241:625-633.

13. Jimsheena VK, Gowda LR. Colorimetric, high-throughput assay for screening angiotensin I-converting enzyme inhibitors. Anal Chem. 2009;81(22):9388-9394.

14. Gupta AK. Quality standards of Indian medicinal plants. Indian Council of Medical Research, Ansari Nagar. India; 2003.

15. Dandapat S, Sinha MP, Kumar M, et al. Hepatoprotective efficacy of medicinal mushroom Pleurotus tuber-regium. Environ Experim Biol. 2015;13:103-108.

16. Dandapat S, Kumar M, Sinha MP. Pharmacological and phytochemical screening of Aegle marmelos (L.) and Cinnamomum tamala (Buch.-Ham.) leaves for therapeutic efficacy. Mid-East J Sci Res. 2014;22(5):626-632.

17. Habu JB, Ibeh BO. In vitro antioxidant capacity and free radical scavenging evaluation of active metabolite constituents of Newbouldia laevis ethanolic leaf extract. Biol Res. 2015;48(16):1-10.

18. Kanimozhi D, Kandhymathi K, Bharathidasan R, et al. Antioxidant activity, estimation of total phenolic content and tannin of Lecuasa spera and Sassia ariculata. World J Sci Tech. 2011;1(9):11-17.

19. Salar RK, Seasotiya L. Free radical scavenging activity, phenolic contents and phytochemical evaluation of different extracts of stem bark of Butea monosperma (Lam.) Kuntze. Front Life Sci. 2011;5(3-4):107-116.
20. Dandapat S, Kumar M, Ranjan R, et al. Pleurotus tuber- regium (Rumph. ex Fr.) Singer a potent source of antioxidant. Balneo Res $J$ 2018;9(3):228-231.

21. Beg M, Sharma V, Akhtar N, et al. Role of antioxidants in hypertension. J Ind Acad Clinical Med. 2011;12(2):122-127.

22. Vallance P, Collier J, Moncada S. Effects of endothelium-derived nitric oxide on peripheral arteriolar tone in man. Lancet. 1989;2(8670):9971000.

23. Ceriello MDA. Possible Role of Oxidative Stress in the Pathogenesis of Hypertension. Diabetes Care. 2008;31(Suppl 2):S181-184.

24. Ferroni P, Basili S, Falco A, Davi G. Oxidant stress and platelet activation in hypercholesterolemia. Antioxid Redox Signal. 2004;6(4):747-756.

25. Baradaran A, Nasri H, Kopaei MR. Oxidative stress and hypertension: Possibility of hypertension therapy with antioxidants. J Res Med Sci. 2014;19(4):358-367.

26. White CR, Brock TA, Chang LY, et al. Superoxide and peroxynitrite in atherosclerosis. Proc Natl Acad Sci US A. 1994;91:1044-1048.

27. Suluvoy JK, Grace VMB. Phytochemical profile and free radical nitric oxide (NO) scavenging activity of Averrhoa bilimbi L. fruit extract. 3 Biotech. 2017;7(1):85.

28. Gadhvi R, Mishra GJ, Reddy MN, et al. Antihypertensive efficacy of Lippia nodiflora - whole plant on uninephrectomized doca - salt hypertensive rats. J Pharma. 2012;2(6):24-28.

29. King VF, Garcia ML, Himmel D. Interaction of tetrandrine with slowly inactivating calcium channel modulation by an alkaloid of chinese medicinal herb origin. J Biol Chem. 1988;263(5):2238-2244.

30. O'Kane PD, Queen LR, Ji Y. Aspirin modifies nitric oxide synthase activity in platelets: Effects of acute versus chronic aspirin treatment. Cardiovas Res. 2003;59(1):152-159.

31. Wu CC, Yen MH. Higher level of plasma nitric oxide in spontaneously hypertensive rats. Am J Hyperten. 1999;12(5):476-482.

32. Adefegha SA, Oyeleye SI, Oboh G. Distribution of phenolic contents, antidiabetic potentials, antihypertensive properties, and antioxidative effects of Soursop (Annona muricata L.) fruit parts in vitro. Biochem Res Int. 2015:347673.

33. Chang CL, Lin CS, Lai GH. Phytochemical characteristics, free radical scavenging activities, and neuroprotection of fivemedicinal plant extracts. Evidence-Based Complement Alternat Med. 2012:984295.

34. Njoya EM, Munvera AM, Mkounga P, et al. Phytochemical analysis with free radical scavenging, nitric oxide inhibition and antiproliferative activity of Sarcocephalus pobeguinii extracts. BMC Complement Alternat Med. 2017;17:199. 